\title{
Time to revisit Dr Finlay's casebook? The unique potential of the general practice case report Christian D Mallen
}

Address: Arthritis Research Campaign National Primary Care Centre, Keele University, Keele, Staffordshire, ST5 5BG, UK

Email: Christian D Mallen - c.d.mallen@cphc.keele.ac.uk

Published: 3 February 2009

Cases Journal 2009, 2:119 doi:10.1186/1757-1626-2-119

This article is available from: http://www.casesjournal.com/content/2/1/1 19

Thillen; licensee BioMed Central Ltd.

This is an Open Access article distributed under the terms of the Creative Commons Attribution License (http://creativecommons.org/licenses/by/2.0), which permits unrestricted use, distribution, and reproduction in any medium, provided the original work is properly cited.

Case reports have played a crucial role throughout the history of medicine. They have been used to describe rare and exceptional diseases, illustrate diagnostic or therapeutic procedures, challenges, actions, errors, and their outcomes $[1,2]$. In the modern era of evidence-based medicine, large-scale population based research and randomised clinical trials we ought not to mourn the passing of eponymous diseases and authoritarian diatribes. But there is still something deeply engaging in the case report that provides a detailed account of an individual patient. It is a form of sharing medical knowledge that general practitioners ought to be at the forefront of. Furthermore it is within the grasp of each and every general practitioner to make their contribution. So what's holding us back?

Cases seen in general practice are frequently seen as being routine and unspectacular. Whilst this may be true in terms of their actual diagnosis, when other components, such as multimorbidity, social disadvantage, psychological characteristics, are added into the equation the unique potential of general practice cases is realised. More than any other group general practitioners are able to appreciate illness (the ill health a patient identifies themselves with, usually based on self-reported psychological or physical symptoms) rather than disease (the biological process that doctors use to explain and understand illness) [3], with knowledge of the patient over time and of his or her family and community. This information represents an essential component to the successful management of our patients, yet these components could never be captured in a randomised controlled trial or large prospective cohort.
Received: 6 October 2008

Accepted: 3 February 2009
It is not as if general practitioners are unaware of the importance and usefulness of case reports. They have been used as teaching instruments for many years and the Royal College of General Practitioners have recently introduced case-based discussions as a core part of the Workplace Based Assessment (WPBA) component of the new Membership of the Royal College of General Practitioners (nMRCGP) examination [4]. Yet in primary care we fail to have a strong tradition of publishing our interesting cases, unlike our secondary care colleagues. In a recent review of the first 100 cases published in the Journal of Case Reports not one was contributed by a GP despite the editor being a general practitioner and a Professor of Family Medicine [5]. This is disappointing as most patients' journey starts (and ends) in primary care, often with undifferentiated symptoms that take time to reveal themselves. This filtering and interpretation of multiple physical symptoms, entwined with social and psychological complexities, forms a significant part of clinical practice and only the generalist can fully appreciate the challenges associated with successful management of such patients.

Until now one barrier to publishing cases in primary care has been the lack of a suitable outlet. Specialist journals thrive on the 'weird and the wonderful' case reports submitted to them by secondary care clinicians. General practice has had fewer options for publishing case reports and so we should welcome a new open access journal with a philosophy that encourages us to share our wealth of experience. Observation of individuals in clinical practice has formed the basis of clinical epidemiology and general practitioners, who see around 30 patients a day, collect a myriad of such observations every week. Other editorials published by this journal have noted that for a 'case bank' 
to be truly successful, and informative to clinical care, cases need to be available in huge numbers [5-7]. This does not seem possible without significant general practice input.

As general practitioners, we share cases with our clinical partners everyday and we all learn from these informal experiences. Despite the potential of sharing this with a wider audience, GPs have no real tradition of publishing case reports. Whilst our colleagues in secondary care often publish for career advancement, primary care physicians do not. Time in general practice is an important commodity, and being self employed often results in a 'time is money' scenario in which publishing case reports may be considered to be a low priority. Fortunately new incentives for general practitioners to publish case reports are emerging. The creation of dedicated Academic Vocational Training Schemes [8] will produce a new generation of research-aware clinicians and the introduction of revalidation and a self-nomination process for Fellowship of the Royal College of General Practitioners may encourage established clinicians to submit their case reports for publication, a process that is facilitated by the use of a standardised proforma and the innovative use of video case reports by Cases Journal.

In the 1960's, one of the most popular television programmes broadcast on British television was Dr Finlay's casebook, written by Dr AJ Cronin [9]. Every week millions of people tuned into watch the daily medical needs of the sleepy lowland community of Tannochbrae in rural Scotland [9]. If Dr Finlay was willing to share his casebook with you, shouldn't we all be returning the favour?

\section{Acknowledgements}

The author would like to thank Dr George Peat and Dr Mark Porcheret for commenting on earlier drafts of this paper

CD Mallen is funded by an Arthritis Research Campaign Primary Care Fellowship.

\section{References}

I. Aronson J, Hauben M: Anecdotes that provide definitive evidence. BMJ 2003, 333:1267-1269.

2. Loke Y, Price D, Derry S, Aronson J: Case reports of suspected adverse drug reactions - systematic literature survey of follow-up. BMJ 2006, 332:335-339.

3. Wikman A, Marklund S, Alexanderson K: Illness, disease, and sickness absence: an empirical test of differences between concepts of ill health. Journal of Epidemiology and Community Health 2005, 59:450-454.

4. Royal College of General Practitioners - Curriculum and Assessment Site [http://www.rcgp-curriculum.org.uk/ examinations and assessment.aspx]

5. Kidd M, del Olmo Fernandez S, Saltman D: Journal of Medical Case Reports: the first 100 cases. Journal of Medical Case Reports 2008, 2:168.

6. Smith R: Why do we need Cases Journal? Cases Journal 2008, I:I.

7. Jefferson T: More cases, doctor? Yes please! Cases Journal 2008, I:38.
8. Mallen C, Cooper V: An academic vocational training scheme for general practice: a model for the future? Education for Primary Care 1 5:67-573.

9. Cronin AJ: Short stories from Dr. Finlay's casebook. Longman: London; 1978.
Publish with Bio Med Central and every scientist can read your work free of charge

"BioMed Central will be the most significant development for disseminating the results of biomedical research in our lifetime. " Sir Paul Nurse, Cancer Research UK

Your research papers will be:

- available free of charge to the entire biomedical community

- peer reviewed and published immediately upon acceptance

- cited in PubMed and archived on PubMed Central

- yours - you keep the copyright

Submit your manuscript here:

http://www.biomedcentral.com/info/publishing_adv.asp 